\title{
点接触における電子トンネル効果の熱起電力*
}

\author{
土方邦夫*1, 伊 藤衡平*2, 中別府 修*1 \\ Patric E. PHELAN*3, 鳥越邦 和*4
}

\section{Thermoelectric Voltage at Point Contacts by Electron Tunneling Effect}

\author{
Kunio HIJIKATA, Kohei ITO, Osamu NAKABEPPU, \\ Patric E. PHELAN and Kunikazu TORIKOSHI
}

\begin{abstract}
When a temperature drop exists across a point contact which is formed by pressing a metal whisker against a metal plate, the thermoelectric voltage can be measured, even though the entire electric circuit is made from the same metal. This phenomenon is a result of the characteristic thermoelectric power (TEP), which depends on the electron tunneling effect through a severalangstroms-thick oxide layer at the point contact. In this study, the experimental values and theoretical values of the TEP are compared. There is a possibility of producing a new type of thermal probe using this point contact apparatus.
\end{abstract}

Key Words: Thermophysical Property, Thermoelectric Power, Tunneling Effect, Point Contact, Thermoelectric Voltage

\section{1. 緒言}

金属平板(プレート)と鋭く先端の尖った金属針(ウィ スカ)を図1のように点接触させ，熱起電力を測定す る方法は，電子ーフォノン非平衡状態の研究を行なう ための一つの手段として用いられてきた。接触径が金 属内自由電子の平均自由行程(MFP) と同程度になるた め, 非平衡状態が生じ，これにより熱起電力が発生す る。一般にMFPが大きい極低温で，実験が行なわれて きた。

例えば図 1 に示す様な回路を，全て同じ金属で製作 した場合，回路内の温度が一様でない時には，熱起電 力は掗いに打ち消し合い，結果的に起電力を発生し ない，しかし，点接触部分の断面積を減少させるにし たがい，その部分が非平衡となるため，その熱電能 $S p c$ が, 準平衡状態における材料の熱電能S bulkとは異 なった值を持つようになる．このため接触断面積があ

* 平成 5 年 5 月 27 日 第 30 回日本伝熱シンポジウムにおい て講演, 原稿受付 平成 5 年 9 月 9 日.

*1 正員, 東京工業大学（ $\boldsymbol{E} 152$ 東京都目黒区大岡山 2-12-1)

*2 准員, 東京工業大学大学院.

*3 八ワイ大学 (Honolulu, HI 96822 U. S. A.).

*4 正員, ダイキン.業（⑤91 堺市金岡町 1304）。
る程度小さくなると起電力が生じるようになる。この 時測定される起電圧 $V$ は，熱電能を測定系の全体にわ たり積分して次式となる(Shklyarevskii $\left.{ }^{(1)}\right)$.

$$
\begin{aligned}
& V=\int_{T_{o}}^{T} S_{b u l k} d T+\int_{T}^{T+\Delta T} S_{p c} d T+\int_{T+\Delta T}^{T_{o}} S_{b u l k} d T \\
& =\int_{T}^{T+\Delta T}\left(S_{p c}-S_{b u l k}\right) d T
\end{aligned}
$$

この熱起電力より電子一フォノンの非平衡が研究さ れていると冒頭で述べたが，本研究ではこの点接触法 を高解像温度場測定法へ応用することを提案する．測

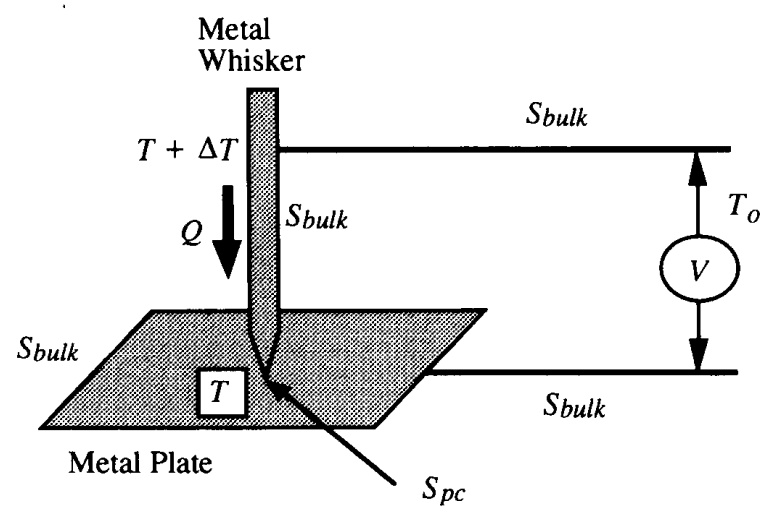

図 1 点接触法の概略図 
定原理は，図1に示した様である。温度測定点に金属

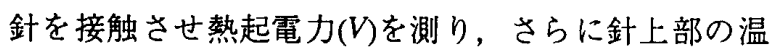
度 $(T+\Delta T)$, 熱電能 $(S p c, S b u k)$ が既知であれば式(1)より 測定点温度 $(T)$ が求まる。な解像度は接触径に依存 するが, 本実験で推定される径は $10^{-6} \mathrm{~m}$ 程度であり， またこれと同程度の精度で針を面方向にスキャンさせ ることは技術的に可能であるので, 点接触法による温 度場測定は高解像が期待できる。

電子デバイス等の製造技術の進展によりその基本と なるスケールが微細化している近年，マイクロスケー ル伝熱問題の解明やこのような高解像温度場測定法の 確立は重要と考えられる。

従来, 点接触によって発生する熱起電力は, 非平衡 効果に基づく熱電能を用いて導出されている，一方， 本研究における実験では，電子のMFPが接触径より短 い温度領域においても，熱起電力が測定された。これ より，Spcが非平衡効果以外の原因で生じた起電力と 考えらる，そこで本研究では現実の点接触部をさらに 考察して, プレートと針表面付近に存在する酸化膜が 起電力の発生の原因と考えて, 理論的検討を行なった (図 2 ). 酸化膜厚さ $a$ が電子波波長 $\lambda$ 程度まで薄くな ると，自由電子はトンネル効果により透過する．この 場合，同一金属からなる回路ではなく，2種類の物質 からなる閉回路となるため，点接触部を通過する熱流 束があれば起電力を生じ，これにより見かけ上点接触 部の熱電能が変化したように見える。無論この場合, 極低温でなくても熱起電力を生じ得る。

電子トンネル効果による熱電能 $S p c$ と金属バルクの
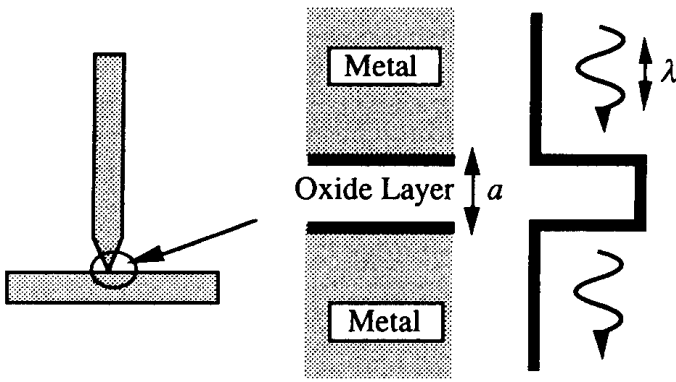

図2 点接触部における酸化膜と電子トンネル効果
熱電能 Sbulkを理論的に求めるとともに，実験を行な い比較検討する。

\section{2. 主な記号}

$$
\begin{aligned}
& a \text { : 酸化膜厚さ } \\
& f \quad \text { : 分布関数 } \\
& f_{o} \quad \text { ：フェルミーディラック分布 } \\
& \text { g : 状態密度 } \\
& j \quad \text { : 電流密度 } \\
& k \quad \text { : 波数 } \\
& k B \quad \text { : ボルツマン定数 } \\
& l \quad: \text { 電子の平均自由行程 } \\
& m \text { ：電子の質量 } \\
& p \quad \text { : 透過率 } \\
& q \quad \text { ：電子の電荷 } \\
& \text { Sbulk ：金属バルクの熱電能 } \\
& S p c \quad ： \text { 点接触部の熱電能 } \\
& T \quad \text { : 温度 } \\
& u \quad \text { : 波動関数 } \\
& V \quad \text { : 電位 } \\
& \text { Vo : 仕事関数 } \\
& x, y, z \quad: \text { 座標 } \\
& \varepsilon \quad \text { ：電子のエネルギ } \\
& \text { ๒ : フェルミエネルギ } \\
& \sigma \quad \text { : 電気伝導率 } \\
& \text { れ : プランク定数 } \\
& \text { 添字 } \\
& \text { wh : 針部 } \\
& p l \quad: \text { プレート部 } \\
& D \text { ：電位を下る方向 } \\
& \text { 1,2,3：領域 }
\end{aligned}
$$

\section{3. 実験}

実験装置を図 3 に示す，金属点接触部の熱起電力を 測定するには，金属針を上下に移動して接触状態を調 整できること，また接触部に温度差をつけることが必 


\section{4. 理論解析}

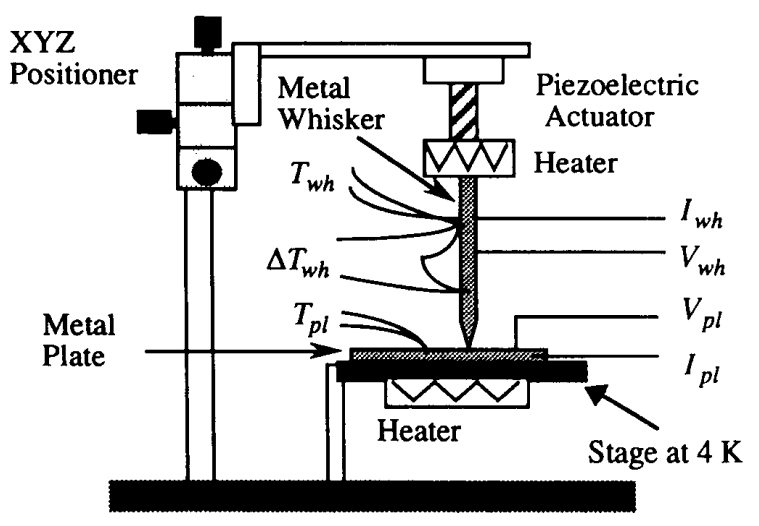

因 3 実験装置

要である．金属針をピエゾアクチュエータとX Y Z ポ シショナにより上下させ，一点接触状態を作る．金属 プレートは常温から4Kまで温度調節可能なステージ 上に設置し，針上部とステージ(Stage at 4K)の下に設 置したヒータにより，点接触部に任意の熱流束を与え る.

$3 つ$ 熱電対 $\left(T_{w h}, \Delta T_{w h}, T_{p}\right)$ を温度場計測のために 用いる. 4 つの電極 $\left(I w h, V_{w h} I p l, V p l\right)$ を用意し, 熱起 電力と点接触部の電気抵抗を測定する。電気抵抗は酸 化膜厚さの見積もりに用いる，金属針は直径 $0.3 \mathrm{~mm}$, 純度99.9\%のCuワイヤの片端をエッチングしてつく り，また金属プレートには純度 $99.9 \%$ ，厚さ $0.3 \mathrm{~mm} の$ 銅板を用いた。 なお図 3 に示す部分全体は極低温装置 内にセットアップされ，10 $10^{-6}$ Torr 程度の圧力下で計測 が行なわれた。

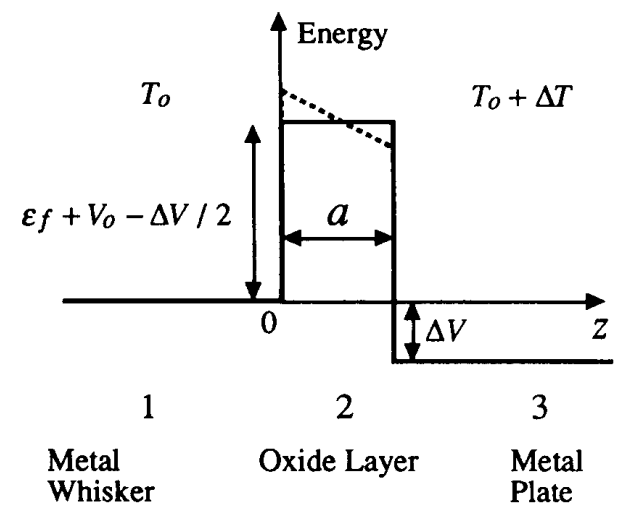

図 4 ポテンシャル形状
熱起電力を理論的に導出するには, バルクの熱電能 Sbulkと点接触部の電子トンネル効果による熟電能 $S_{p c}$ を 求める必要がある，熱電能は，電流密度一電圧特性 $j$ $V$ 特性)を求め, 電流密度 $j$ を零とすることにより求ま る.

$4 \cdot 1$ Sbulkの荋出 従来, 金属バルクの $j \cdot V$ 特性 は，ボルツマン方程式で平衡からのズレが小さいとし て電子分布を与え，例えばMakelvey ${ }^{(2)}$ の著書を参考に して次のように計算される.

$$
\begin{aligned}
& j=\frac{2 q^{3} l m}{3 \pi^{2} \hbar^{3}} \int_{0}^{\infty}\left(\frac{\partial f_{o}}{\partial \varepsilon} \frac{\Delta V}{\Delta z}+\frac{\partial f_{o}}{\partial T} \frac{\Delta T}{\Delta z}\right) \varepsilon d \varepsilon \\
& \text { ここでfoは, } \\
& f_{o}=\frac{1}{1+\exp \left[q\left(\varepsilon-\varepsilon_{f}\right) /\left(k_{B} T\right)\right]}
\end{aligned}
$$

であり，温度てにおけるフェルミーディラック分布で ある. $q$ は電子の電荷, $l$ は電子の平均自由行程, $\varepsilon$ は エネルギ， $\mathrm{z}$ は座標軸である. 式(2)の右辺第一項は電 界によるドリフト電流を表し，第二項は電子の温度勾 配による拡散を示している，全てのエネルギに対し積 分すれば電流密度が得られる。

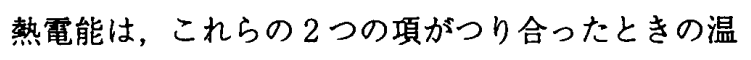
度差あたりの電位差であるから式(2)で $j=0$ としてえら れる. $\mathrm{Cu} の フ ェ ル ミ レ ヘ ゙ ル \varepsilon ~ f^{(3)}$ を代入して, 数值積 分し, パラメータを温度 $T$ に取ると, 以下の様に整 理される。

$$
S_{\text {bulk }}=\frac{\Delta V}{\Delta T}=1.37 \times 10^{-9}+3.49 \times 10^{-9} \times T\left[\frac{\mathrm{V}}{\mathrm{K}}\right]
$$

この式で, 絶対 0 度の極限で熱電能が 0 とならないの は，熱物性の温度依存性を正確に考虑していないため であるが, 本研究の対象としている温度領域(30〜 $150 \mathrm{~K})$ では十分な精度をもつ。

$4 \cdot 2 S_{p c}$ の蒠出 酸化膜を透過する電子のトン ネル効果によるj-V 特性を求めるためには，透過率が 必要である. 図4のように金属一酸化膜一金属の而端 に $\Delta V$ の電圧が印加されていると仮定する.この奄压 印加によりポテンシャル場は破線の様に変化するが, 
ここでは計算の簡単のために酸化膜内の電位分布を実 線の様に平均值で一定とする.

領域 1 から 3 への透過率P13を, 各領域での波動関 数の振幅を求めることにより計算する．各領域でのシ ユレディンガ方程式とその一般解は,

Region $1 \quad-\frac{\hbar^{2}}{2 m} \frac{d^{2} u_{1}}{d z^{2}}=\varepsilon u_{1}$

$$
\begin{aligned}
& u_{1}=A \exp \left(i \alpha_{13} z\right)+B \exp \left(-i \alpha_{13} z\right) \\
& \text { where } \quad \alpha_{13}=\sqrt{\frac{2 m \varepsilon}{\hbar^{2}}}
\end{aligned}
$$

Region $2-\frac{\hbar^{2}}{2 m} \frac{d^{2} u_{2}}{d z^{2}}+\left(\varepsilon_{f}+V_{o}-\Delta V / 2\right) u_{2}=\varepsilon u_{2}$ $u_{2}=F \exp \left(\beta_{13} z\right)+G \exp \left(-\beta_{13} z\right)$

where $\quad \beta_{13}=\sqrt{\frac{2 m\left(\varepsilon_{f}+V_{o}-\Delta V / 2-\varepsilon\right)}{\hbar^{2}}}$

Region $3 \quad-\frac{\hbar^{2}}{2 m} \frac{d^{2} u_{3}}{d z^{2}}=(\Delta V+\varepsilon) u_{3}$

$$
\begin{aligned}
& u_{3}=H \exp \left(i \gamma_{13} z\right) \\
& \text { where } \quad \gamma_{13}=\sqrt{\frac{2 m(\Delta V+\varepsilon)}{\hbar^{2}}}
\end{aligned}
$$

ここでVoは仕事関数, $\varepsilon_{f}$ はフェルミレベルである.

境界条件は，波動関数とその微分が各境界面で等し いことから, 次の様である。

$$
\begin{array}{lll}
\text { at } z=0 & u_{1}=u_{2}, & \frac{d u_{1}}{d z}=\frac{d u_{2}}{d z} \\
\text { at } z=a & u_{2}=u_{3}, & \frac{d u_{2}}{d z}=\frac{d u_{3}}{d z}
\end{array}
$$

透過率 $\left(\right.$ Schiff $\left.{ }^{(4)}\right)$ は次式で定義される。

$$
P_{13}=\frac{\gamma_{13}}{\alpha_{13}}\left|\frac{H}{A}\right|^{2}
$$

$H / A$ を式(4), (5)より求めると, 結局透過率は次式で 与えられる。

$P_{3}=$

$$
\frac{4 \alpha_{13} \beta_{13}{ }^{2} \gamma_{13}}{\left[\sinh \left(\beta_{13} a\right)\left(\alpha_{13} \gamma_{13}-\beta_{13}{ }^{2}\right)\right]^{2}+\left[\cosh \left(\beta_{13} a\right)\left(\alpha_{13}+\gamma_{13}\right) \beta_{13}\right]^{2}}
$$

領域1から3へは電子を加速する方向にポテンシャル が印加されているが, 領域3から1への電子の流れはこ のポテンシャルにより減速される方向になる．この点 を考虑して，つまり $\beta_{13}$ 中の- $\Delta V / 2$ を $\Delta V / 2$ に置き換 え, $\gamma 13$ 中の $\Delta V$ を $-\Delta V に$ 置き換えると逆方向の透過 率P31を同様に求めることができる.
領域 1 から 3 への電流密度 $j 13$ は, 透過率を用いて 次式で与えられる(Majumdar ${ }^{(5)}$ ).

$$
j_{13}=\int_{0}^{\infty} \int_{\infty}^{\infty} \int_{\infty}^{\infty}(-q) v_{z} g P_{3} f_{1}^{D}\left(1-f_{3}^{D}\right) d k_{x} d k_{y} d k_{z}
$$

ここで $g\left(=2 /(2 \pi)^{3}\right)$ は状態密度, $k x, k y, k z$ は波数空間 を表し， $f_{1}^{D}, f_{3}^{D}$ はそれぞれ領域1，3におけるフェ ルミーディラック分布で次式で与えられる.

$$
\begin{aligned}
f_{1}^{D} & =\frac{1}{1+\exp \left[q\left(\varepsilon-\varepsilon_{f}\right) /\left(k_{B} T_{o}\right)\right]} \\
f_{3}^{D} & =\frac{1}{1+\exp \left[q\left(\varepsilon+\Delta V-\varepsilon_{f}\right) /\left(k_{B}\left(T_{o}+\Delta T\right)\right)\right]}
\end{aligned}
$$

式(8)中における $\left(1-f_{3}^{D}\right)$ は，電子が異なる平衡状態 の領域に入り込むために，透過後の領域に空席が必要 であることを示している。

一方, 領域 3 から 1 への電流密度も全く同様にして 得られる。全電流密度 $j$ は $j_{13}$ と $j_{31}$ の和で与えられる から，

$$
j=j 13+j 31
$$

今，図 4 における初期の温度差 $\Delta T$, 電位差 $\Delta V$ が小 さいとして展開すれば,

$$
j=\left.\frac{\partial j}{\partial V}\right|_{\substack{V=0 \\ T=T_{o}}} \Delta V+\left.\frac{\partial j}{\partial T}\right|_{\substack{V=0 \\ T=T_{o}}} \Delta T
$$

となる

電子トンネル効果による熱電能Spcは，Sbulkを求めた ときと同様にして式(11)で $j=0$ とおいて求まる， $\mathrm{Cu}$ の 物性値 $\left(\varepsilon f, V_{o}\right)$ を代入して，数値積分して整理すると 温度 $T_{o}$, 酸化膜厚さ $a$ の関数として次式が与えられ る.

$$
\begin{aligned}
S_{p c} & =\frac{\Delta V}{\Delta T}=-\left.\frac{\partial j}{\partial T}\right|_{\substack{V=0 \\
T=T_{o}}} /\left.\frac{\partial j}{\partial V}\right|_{\substack{V=0 \\
T=T_{o}}} \\
& =\left(3.56 \times 10^{-9}+2.27 \times 10^{-9} \times T_{o}\right) \\
& +\left(-35.5+60.1 \times T_{o}\right) \times a \quad\left[\frac{\mathrm{V}}{\mathbf{K}}\right]
\end{aligned}
$$

\section{5. 結果と考案}

実験から得られる熱電能と理論計算により得られる 
熱電能を比較するために，針とプレートの接触断面積

と，酸化膜厚さを推定しなければならない.

接触断面積は，円錐部の温度勾配が急激で酸化膜の 厚さが十分薄いと仮定すると, 熱量のバランスからお よそ $10^{-12} \mathrm{~m}^{2}$ と求められる。この接触断面積を用い,

電流密度一電圧を図 5 にプロットする，図中の線は式 (10)による理論計算の結果である。等価的な酸化膜厚

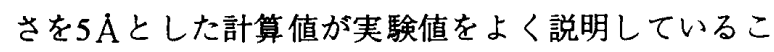
とがわかる。一方，この時の $\mathrm{Cu}$ の電気伝導率 $\sigma$ から計 算される電流密度は,

$$
\begin{aligned}
j=\sigma \frac{V}{a} & =5.88 \times 10^{7} \times \frac{30 \times 10^{-3}}{5 \times 10^{-10}} \\
& =3.5 \times 10^{15} \quad\left[\frac{\mathrm{A}}{\mathrm{m}^{2}}\right]
\end{aligned}
$$

となっており，本研究での実験值より6析ほど大きい ことから，実験値で得られた電流はトンネル電流と考 えてよいことが分かる。

これらの酸化膜厚さを用い計算される電子トンネル

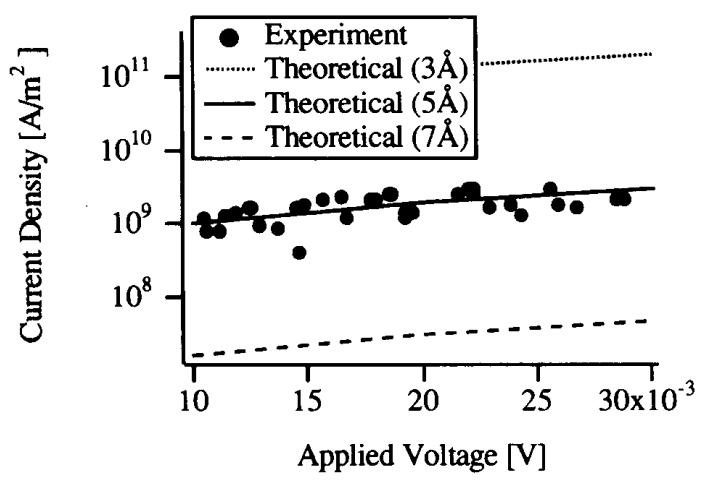

図 5 点接触部における $j-V$ 特性

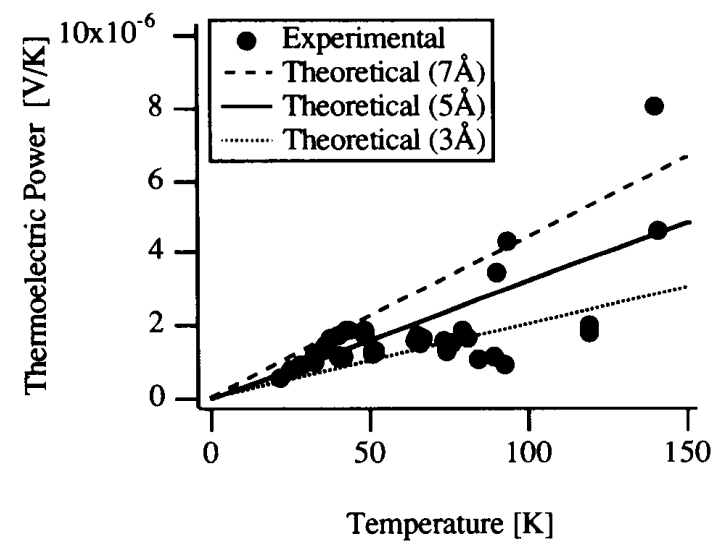

図 6 電子トンネル効果による熱電能
効果による熱電能Spcが, 図 6 に示してある。理論計 算値は温度に対してリニアに増加するが，実験值もこ の傾向を示している.この結果からも電流密度一電圧 特性から得られた $5 \AA$ の酸化膜厚さが実験值をよく説 明していることが分かる。

本研究では実験上プレート温度と針温度の変化しう る範囲が限られており，プレート温度150K以下では 熱流束が針からプレートに向っており，それ以上の温 度ではプレートから針へと流れる。このため150K近 傍では熱流束が小さくなり，充分な実験精度が得られ なかったため, 本研究ではプレート温度 $150 \mathrm{~K}$ 以下の 場合のみ示してある.

\section{6. 結言}

金属点接触部の熱電能を電子トンネル効果として理 論解析すると, 実験を行なった温度範囲で理論值と実 験值の一致がみられた。

熱電能を理論的に予測することができるので点接触 法を温度測定に利用できる可能性があり，さらにその 分解能が接触断面積程度 $\left(10^{-12} \mathrm{~m}^{2}\right)$ である点を考虑する と高解像度の温度測定法として応用できる可能性があ る.

\section{7. 参考文献}

(1) Shklyarevskii,O.I., Jansen,A.G.M., Hermsen,J.G.H., and Wyder,P., Physical Review Letters, 57-11 (1986), 1374.

(2) Mckelvey,J.P., Solid State and Semiconductor Physics, (1986), 180, Robert E. Krieger Publishing Company.

(3) Burms,G., (長尾辰哉ほか 4 名訳), 固体の電子論, (1991), 2, 東海大学出版会.

(4) Schiff, L.I., Quantum Mechanics, International Student Edition, (1968), 100, McGraw-Hill.

(5) Majumdar, A., "Quantum Heat Transport by Electron Tunneling", 28th National Heat Transfer Conference and Exhibition, HTD-Vol.200 (1992), 71. 